\title{
PENGARUH PERMAINAN TRADISIONAL ENGKLEK TERHADAP POWER OTOT TUNGKAI PADA SISWA KELAS III SD SWASTA AMAL BAKTI TAHUN AJARAN 2019/2020
}

\author{
Devi Catur Winata \\ Pendidikan Jasmani Kesehatan Dan Rekreasi Stok Bina Guna Medan \\ devicatur25@gmail.com
}

\begin{abstract}
ABSTRAK
Penelitian ini bertujuan untuk mengetahui pengaruh permainan tradisional engklek terhadap power otot tungkai pada siswa kelas III SD Swasta Amal Bakti Tahun Ajaran 2019/2020. Penelitian ini merupakan Penelitian eksperimen. Penelitian ini dilaksanakan dengan cara mengambil data awal (pretest) kemudian melakukan perlakuan (treatmen) dan setelah itu melakukan tes akhir (posttest). Sumber data dalam penelitian ini adalah hasil tes siswa yang berbentuk unjuk kerja (psikomotor). Untuk menganalisis data dalam penelitian ini dan untuk mengetahui hasil penelitian dilihat hasil post test.

Analisis hipotesis dari pre-test dan post-test dari pengaruh permainan tradisional engklek diperoleh $t_{\text {hitung }}$ sebesar 7,120 dan $t_{\text {tabel }}$ sebesar 1,70 dengan taraf sigifikan $\alpha=0,05$ artinya $t_{\text {hitung }}>t_{\text {tabel }}$ berarti $H_{o}$ ditolak dan $H_{a}$ diterima. Jadi dapat disimpulkan bahwa permainan tradisional engklek memberikan pengaruh yang signifikan terhadap aktivitas gerak dasar lompat pada Siswa Kelas III SD Swasta Amal Bakti Tahun pelajaran 2019/2020.
\end{abstract}

Kata kunci : Permainan tradisional engklek, power otot tungkai

\section{The Influence Of Traditional Engklek Games On Castle Muscle Power In Class Iii Students Of Amal Bakti Private Vocational School 2019/2020}

\begin{abstract}
ABSTRACK
This study aims to determine the effect of traditional crank play on leg muscle power in third grade students of Private Charity Charity Elementary School in 2019/2020. This research is an experimental research. This research was conducted by taking the initial data (pretest) and then doing the treatment (treatment) and after that doing the final test (posttest). The data source in this study is the results of student tests in the form of performance (psychomotor). To analyze the data in this study and to find out the results of the study seen the results of the post test.

Hypothesis analysis from the pre-test and post-test of the influence of the traditional game crank obtained tcount of 7.120 and ttable of 1.70 with a significant level $\alpha=0.05$ means tcount $>$ ttable means Ho is rejected and Ha is accepted. So it can be concluded that the traditional game of crank gives a significant influence on the basic jumping activity of Class III Students of Private Charity Charity Elementary School 2019/2020.
\end{abstract}

Keywords: Traditional Crank Play, Leg Muscle Power

Dipublikasikan Oleh :

UPT Publikasi dan Pengelolaan Jurnal

Universitas Islam Kalimantan Muhammad Arsyad Al-Banjari Banjarmasin 


\section{PENDAHULUAN}

Pendidikan jasmani merupakan mata pelajaran yang diajarkan mulai pendidkan dasar sampai pendidikan menengah atau kejuruan. Melalui proses pendidikan jasmani, olahraga dan kesehatan diharapkan dapat mendorong pertumbuhan fisik, keterampilan motorik serta pengetahuan. Pendidikan jasmani sebagai komponen pendidikan secara keseluruhan telah disadari oleh semua kalangan. Namun, pelaksanaannya pendidikan jasmani berjalan belum efektif seperti yang diharapkan. Peran pendidikan jasmani sangat penting, yakni memberikan kesempatan kepada siswa terlibat langsung dalam aneka gerak pengalaman belajar melalui aktivitas jasmani. Hal tersebut merupakan media untuk mendorong perkembangan keterampilan motorik, kemampuan fisik, pengetahuan dan penalaran, penghayatan nilai-nilai (sikap mental, emosional, spiritual dan sosial), serta membiasakan pola hidup sehat yang bermuara untuk merangsang pertumbuhan dan perkembangan yang seimbang.

Tujuan utama pembelajaran pendidikan jasmani di Sekolah Dasar adalah membantu peserta didik agar meningkatkan keterampilan gerak mereka, disamping agar mereka merasa senang dan mau berpartisipasi dalam berbagai aktivitas. Prinsip penting dalam pelajaran pendidikan jasmani di SD harus menekankan berpartisipasi aktif dan merata serta berpusat pada anak didik, artinya adalah bahwa seorang guru pendidikan jasmani harus menyajikan materi sesuai dengan tingkat kemampuan anak didik. Materinya meliputi gerak sehari-hari, mulai dari : merayap, merangkak, melompat, berjalan, berlari, memanjat, berayun, berguling, berjingkat, menggendong, melempar, menangkap, memukul, mengangkat, menahan, mendorong, manarik dan seterusnya.

Permainan tradisional merupakan jenis permainan yang mengandung nilai-nilai budaya yang pada hakikatnya merupkan warisan leluhur yang harus dilestarikan keberadaannya. Dalam permainan tradisional ada permainan yang bersifat bertanding dan ada juga permainan yang diutamakan hanya sebagai rekreasi atau dengan kata lain mengisi waktu luang. Pengelompokan permainan ini sendiri ada yang bersifat individu, beregu, dan juga antara kelompok. Jika kita mengamati aktivitas yang dilakukan oleh anak permainan tradisional membutuhkan kesiapan fisik yang baik, karena membutuhkan keterampilan seperti kecekatan kaki dan tangan, ketajaman berfikir / menganalisa serta keluwesan / fleksibilitas tubuh yang baik. Permainan tradisional itu sendiri juga banyak memadukan unsur kesenian seperti tarian, nyanyian bahkan unsur magis juga dapat terlibat didalamnya.

Kematangan gerak merupakan hal yang tidak bisa dipandang sebelah mata karena menyangkut kelangsungan hidup manusia dan harus mendapat perhatian yang serius. Kualitas gerak dan fisik yang baik akan mempengaruh kepada kualitas hidup manusia keseluruhan, karena manusia adalah mahluk hidup yang terus bergerak untuk dapat mempertahankan kelangsungan hidupnya, perkembangan kualitas gerak manusia didasarkan kepada perkembangan usia secara normal akan terus berkembang sampai pada puncak pertumbuhan gerak yang optimal.

Menurut Sukirman Dharmamulya (2006:20) dalam bukunya, nilai-nilai budaya yang terkandung dalam permainan tradisional diantaranya : Melatih sikap mandiri, berani mengambil keputusan, penuh tanggung jawab, jujur, sikap dikontrol oleh lawan, kerjasama, saling membantu dan menjaga, membela kepentingan kelompok, berjiwa demokrasi, patuh pada peraturan, penuh perhitungan, ketepatan berfikir dan bertindak, tidak cengeng, berani, bertindak sopan, bertindak luwes. Demikian banyak nilai yang terkandung dalam permainan tradisional. Muatan pendidikan dan juga nilai-nilai kemanusiaan yang kreatif dan handal akan terbentuk dalam jiwa anak sehingga tak akan pantang menyerah.

Sejalan dengan itu Suherman dan Mahendra (2001:6) "pembelajaran keterampilan gerak anak menguasai keterampilan dalam berbagai cabang olahraga merupakan tanggung jawab utama dari guru pendidikan jasmani". Merujuk dari apa yang dikatakan oleh ahli tersebut, jelas perkembangan dan pertumbuhan seoarang siswa merupakan tanggung jawab dari guru penjas maka dari itu guru pendidikan jasmani dapat mengadopsi permainan tradisional menjadi salah satu materi yang diajarkan dalam pembelajarannya

Sarana pembelajaran olahraga dapat dimodifikasi agar pembelajaran tersebut tetap dapat dilaksanakan sesuai dengan tuntutan kurikulum tetapi tidak lari metode yang telah di tentukan. Metode yang dapat digunakan untuk mengajar keterampilan dalam gerak dasar lompat pada prinsipnya sama dengan pe manfaatan metode mengajar atau metode latihan untuk setiap jenis keterampilan. Menurut Rorimpandey (2008:54) "Gerak dasar lompat yang dimaksud dalam klasifikasi jenis keterampilan yang bersifat kombinasi asiklis (acyclic combined). Artinya ada gerakan siklis yang kemudian dilanjutkan dengan gerakan asiklis sehingga dapat memanfaatkan metode bagian (part method) maupun keseluruhan (whole method)".

Dipublikasikan Oleh :

UPT Publikasi dan Pengelolaan Jurnal

Universitas Islam Kalimantan Muhammad Arsyad Al-Banjari Banjarmasin 
Seopartono (2001:19) "Modifikasi gerak dasar melompat dapat dilakukan dengan berbagai cara dengan menggunakan peralatan berupa: kotak, ban dan tali, yang ditata sedemikian rupa, baik jarak, rangkaian, formasi, maupun tinggi atau lebarnya". Adapula dengan berbagai bentuk permainan, baik itu permainan yang dimodifikasi ataupun permainan tradisional yang diangkat kembali dalam pembelajaran. Sehingga pendekatan modifikasi ini dimaksut agar materi yang ada dalam kurikulum dapat disajikan sesuai dengan tahapan-tahapan perkembangan kognitif, afektif, dan psikomotor anak.

Menurut Sukadiyanto (2002) mengemukakan " latihan berasal dari kata dalam bahasa Inggris yang dapat mengandung beberapa makna seperti: practise, excercises, dan training",(hlm.16). Sejalan dengan apa yang dikatakan Bompa (1994) "latihan biasanya didefenisikan sebagai suatu proses sistematis yang dilakukan dalam jangka waktu panjang, berulang-ulang, progresif, dan mempunyai tujuan untuk meningkatkan penampilan fisik". (hlm.23)

Menurut Tangkudung (2012) "latihan atau training adalah proses yang sistematis dari berlatih yang dilakukan secara berulang-ulang dengan kian hari kian menambah jumlah beban latihan serta intensitas latihannya" (hlm.36). Selanjutnya menurut Harsono (2000) "latihan adalah proses yang sistematis dari berlatih atau bekerja, yang dilakukan secara berulang-ulang, dengan kian hari kian menambah jumlah beban latihan atau pekerjaannya" (hlm.36).

Menurut Sukintaka (2004) "karakteristik perkembangan motorik anak usia 6-12 tahun adalah sebagai berikut. Karakteristik jasmani anak 6-8 tahun (kelas I-II) antara lain : (1) waktu reaksi lambat, (2) aktif, energik dan senang kepada suara berirama, (3) tulang lembek dan mudah berubah bentuk, (4) jantung mudah dalam keadaan yang membahayakan, (5) rasa untuk mempertimbangkan dan pemahaman berkembang, (6) koordinasi mata dan tangan berkembang masih tetap belum dapat menggunakan otot-otot halus dengan baik, (7) kesehatan umum tidak menentu, mudah terpengaruh terhadap penyakit, dan daya perlawanannya rendah" (hlm.24). Umur 6-8 tahun kemampuan motoriknya antara lain : (1) keterampilan dalam menggunakan mekanika tubuh yang baik dalam berbaring, duduk, berjalan dan berlari, (2) mengembangkan keseimbangan tendon otot dan kekuatan otot untuk membentuk tubuh yang layak dan benar, (3) mengembangkan keterampilan dan relaksasi; mengembangkan latihan kekuatan, kecepatan, kelincahan, dan daya tahan untuk berpartisipasi dalam aktivitas.

\section{METODE}

Penelitian ini menggunakan metode eksperimen dengan rancangan pre-test dan post-test. Pre-test adalah tes awal yang dilakukan untuk melihat kemampuan dasar dari siswa yang menjadi sampel sedangkan post-test adalah tes yang dilakukan setelah sampel diberikan perlakuan (treatment). Pre-test dilakukan di awal sebelum pertemuan sedangkan post-test dilakukan di akhir pertemuan.

Variabel yang ada dalam peneilitain ini ada dua yaitu variabel bebas dan variabel terikat. Berikut penjelasan dari tiap variabel:

1. Variabel Bebas : Permainan tradisional Engklek

2. Varaiabel Terikat: Power otot tungkai

Penelitian ini dilakukan di Sekolah Dasar Negeri 050635 SD Swasta Amal Bakti Tahun Pelajaran 2019/2020 . Dengan lamanya penelitian 4 kali pertemuan (4x35 menit) di bulan September 2019. Dalam hal ini peneliti mengambil sampel penelitian dengan teknik random sample atau sampel acak yaitu siswa/i kelas 3-A dengan jumlah siswa 22 orang.

Desain Penelitian yang digunakan dalam penelitian ini adalah peneliti melakukan uji awal untuk melihat kemampuan dasar dari siswa kelas 3 sebagai sampel (pre-test) yang kemudian peneliti akan memberikan perlakuan (treatment) pada sampel penelitian berupa permainan engklek dalam beberapa pertemuan yang selanjutnya diakhir pertemuan peneliti melaksanakan tes akhir (post-test) untuk melihat perubahan/keberhasilan perlakuan. Untuk lebih jelasnya dapat dilihat pada desain penelitian berikut :

Tabel .1 Desain Penelitian

\begin{tabular}{|l|l|l|}
\hline 1 & 2 & 3 \\
Pre-test & Treatment & Post-test \\
\hline
\end{tabular}

Dipublikasikan Oleh :

UPT Publikasi dan Pengelolaan Jurnal

Universitas Islam Kalimantan Muhammad Arsyad Al-Banjari Banjarmasin 
"Instrumen adalah alat pada waktu penelitian menggunakan suatu metode" (Arikunto 2002:126). Intrumen yang digunakan dalam penelitian ini adalah bentuk tes yang dinilai dapat mengukur power otot tungkai pada anak usia Sekolah Dasar kelas 3 dengan menggunakan Standing long JumpTest atau Loncat Tanpa Awalan (Widiastuti 2011). Berikut pelaksanaannya:

a. Tujuan pelaksanaan tes ini adalah mengukur kemampuan power tungkai.

b. Alat dan bahan : Peralatan Pita ukur / meteran, garis tanda, serta landasan yang relatif empuk seperti matras dan sejenisnya.

c. Pelaksanaan :

Posisi awal : Siswa berdiri di belakang garis dengan kedua kaki sedikit terbuka, bengkokkan lutut dan ayunkan kedua lengan ke belakang dan kedepan sebagai persiapan meloncat.

Unjuk kerja :Siswa meloncat ke depan, mendarat dengan satu atau dua kaki; lakukan tiga kali loncatan.

d. Penilaian: Nilainya adalah jarak loncatan (feet aut inci) antara garis start sampai titik tumit terdekat. Hanya loncatan terbaik dari ketiga loncatan yang dicatat. Apabila siswa jatuh atau melangkah mundur setelah mendarat, pengurukuran dilakukan dari tempat sentuhan bagian tubuh yang paling dekat pada garis atrat, dibanding dengan tempat pendaratan awal.

\section{HASIL DAN PEMBAHASAN}

Tes dan pengukuran serta evaluasi yang dilakukan dilapangan selama 4 minggu dilakukan untuk mengungkapkan kebenaran hipotesis yang telah diajukan. Dari hasil pre-test yang dilakukan diperoleh rentang nilai 1,19-1,63dengan rata-rata 1,42 dan simpangan baku 0,14 Kemudian diberikan perlakuan (treatment) untuk kemudian setelah itu dilakukan uji/tes kembali (post-test). Dari hasil post-test diperoleh rentang nilai 1,27-1,69 dengan rata-rata 1,50 dan simpangan baku 0,12

Kemudian dari rata-rata pre-test dan post-test dapat dilihat nilai beda rata-rata 0,079 dengan simpangan baku 0,063 sehingga didapat $t_{\text {hitung }} 7,120$ dengan $\alpha=0,05 \mathrm{t}_{\text {tabel }}$ didapat sebesar 1,70

Tabel 4.1 Hasil Pre tes dan Post tes

Pengaruh Permainan Tradisional Terhadap Power Otot Tungkai

\begin{tabular}{|l|l|l|l|l|}
\hline \multirow{2}{*}{$\begin{array}{l}\text { Deskripsi } \\
\text { Data }\end{array}$} & \multicolumn{3}{|l|}{ Gerak Dasar Lompat } \\
\cline { 2 - 5 } & \multicolumn{2}{|l|}{ Pre-test } & \multicolumn{2}{l|}{ Post-test } \\
\hline Rentang & 1,19 & 1,63 & 1,27 & 1,69 \\
\hline Rata-rata & 1,42 & 1,50 & \\
\hline $\begin{array}{l}\text { Simpangan } \\
\text { Baku }\end{array}$ & 0,14 & 0,12 \\
\hline Beda rata-rata & 0,079 & \multicolumn{2}{|l}{} \\
\hline
\end{tabular}

Tabel 4.2 Uji Normalitas

\begin{tabular}{|c|c|c|c|c|c|}
\hline $\begin{array}{l}\text { Perlaku } \\
\text { an }\end{array}$ & $\begin{array}{ll}\text { Rata-rata dan } \\
\text { Simp. Baku }\end{array}$ & $\mathrm{L}_{0}$ & $\mathrm{~L}_{\text {tabel }}$ & $\alpha$ & Ket \\
\hline \multirow{2}{*}{$\begin{array}{l}\text { Permain } \\
\text { an } \\
\text { Engklek }\end{array}$} & $\begin{array}{l}\text { Pre-test } \\
\bar{X}=1,42 \\
\mathrm{~S}=0,140\end{array}$ & $\begin{array}{l}0,48 \\
6\end{array}$ & \multirow{2}{*}{$\begin{array}{l}0,88 \\
6\end{array}$} & \multirow{2}{*}{$\begin{array}{l}0, \\
0 \\
5\end{array}$} & $\begin{array}{l}\text { Norma } \\
1\end{array}$ \\
\hline & $\begin{array}{l}\text { Post-test } \\
\bar{X}=1,50 \\
\mathrm{~S}=0,122\end{array}$ & $\begin{array}{l}0,64 \\
0\end{array}$ & & & $\begin{array}{l}\text { Norma } \\
1\end{array}$ \\
\hline
\end{tabular}

Pengujian normalitas data dengan menggunakan uji Lilifors dari kolom pre-test diatas, pengaruh permainan tradisional engklek terhadap aktivitas gerak dasar didapat $\mathrm{L}_{0}=0,486$ dan $\mathrm{L}_{\text {tabel }}=0,886$ dengan $\mathrm{n}=32$ dan taraf

Dipublikasikan Oleh :

UPT Publikasi dan Pengelolaan Jurnal

Universitas Islam Kalimantan Muhammad Arsyad Al-Banjari Banjarmasin 
signifikan $\alpha=0,05$. Dari data tersebut $\mathrm{L}_{\text {hitung }}<\mathrm{L}_{\text {tabel }}$ dapat disimpulkan bahwa sampel berasal dari populasi yang normal. Selanjutnya dari kolom post-test, pengaruh permainan tradisional engklek terhadap aktivitas gerak dasar didapat $\mathrm{L}_{0}=0,640$ dan $\mathrm{L}_{\text {tabel }}=0,886$ dengan $\mathrm{n}=32$ dan taraf signifikan $\alpha=0,05$. Dari data tersebut $\mathrm{L}_{\text {hitung }}<\mathrm{L}_{\text {tabel }}$ dapat disimpulkan bahwa sampel berasal dari populasi yang normal.

Dari perhitungan varians diperoleh data sebagai berikut:

$$
S_{1}^{2}=1,416 \quad S_{2}{ }^{2}=0,122 \quad \mathrm{n}=32
$$

Dengan Demikian $\mathrm{F}_{\text {hitung }}=\frac{1,416}{0,122}=1,146$

Sedangkan $\mathrm{F}_{\text {tabel }}$ diperoleh dari daftar $\mathrm{F}$ dengan taraf signifikan $\alpha=0,05$ sebesar 3,32 yang berarti $\mathrm{F}_{\text {hitung }}(1,146)<$ $\mathrm{F}_{\text {tabel }}(3,32)$, maka hipotesis $\mathrm{H}_{0}$ diterima.

Berdasarkan hasil perhitungan hipotesis diperoleh nilai post-test $\mathrm{t}_{\text {hitung }}=7,120$ pada taraf signifikan $\alpha=0,05$ dengan $n=32$ dan harga $t_{\text {tabel }}=1,70$. Dengan demikian bila dibandingkan antara $t_{\text {hithung }}(7,120)>t_{\text {tabel }}(1,70)$ sehingga dapat disimpulkan bahwa permainan tradisional engklek memberikan pengaruh yang signifikan terhadap aktivitas gerak dasar lompat pada Siswa Kelas III Sekolah Dasar swasta amal bakti tahun ajaran 2019/2020.

\section{Pembahasan}

Dari hasil pengujian hipotesis menunjukkan bahwa adanya pengaruh yang signifikan antara pre-test dan post-test pada permainan engklek terhadap hasil belajar gerak dasar lompat tanpa awalan pada siswa kelas III Sekolah Dasar Swasta Amal Bakti Tahun pelajaran 2019/2020.

Hal ini membuktikan bahwa dengan melakukan permainan tradisional engklek akan dapat memberikan dampak yang cukup signifikan yaitu meningkatnya aktivitas gerak dasar lompat tanpa awalan pada siswa kelas III Sekolah Dasar. Dengan penerapan permainan engklek ini, siswa tidak merasakan atau menyadari bahwa dirinya sedang dilatih namun siswa larut dalam permainan yang menimbulkan keceriaan sehingga siswa tidak merasa jenuh atau bosan.

Dalam pembelajaran pendidikan jasmani khususnya pada siswa sekolah dasar terlebih lagi pada siswa kelas rendah (kelas III) diperlukannya bentuk-bentuk permainan yang dapat mengakomodir segala kebutuhan siswa, baik itu kebutuhan/nalurinya untuk bergerak dengan leluasa dan lincah maupun mengajarkan siswa bagaimana bersikap, bersosial dan bekerjasama. Untuk itu permainan dianggap media yang sesuai akan pemenuhan kebutuhan tersebut.

Permainan tradisional dianggap kuno dan usang. Namun pada hakikatnya permainan tradisional merupakan media pembelajaran yang sangat hal ini dapat dilihat dari segi gerak psikomotor anak maupun dari segi kognitif dan sosial anak. Semoga dengan peremajaan kembali permainan-permainan tradisional pembelajaran penjas akan lebih menarik disamping pelestarian budaya bangsa. Permainan engklek dianggap relevan terhadap peningkatan kemampuan gerak dasar lompat tanpa awalan, ini dibuktikan dengan penelitian yang telah dilaksanakan oleh peneliti sendiri.

Dari hasil penelitian yang dilakukan hipotesis menunjukkan $\mathrm{H}_{0}$ ditolak dan $\mathrm{H}_{\mathrm{a}}$ diterima. $\mathrm{H}_{0}$ menunjukkan tidak adanya pengaruh yang signifikan antara permainan engklek dengan aktivitas gerak lompat tanpa awalan pada sisiwa kelas III Sekolah Dasar swasta amal bakti Tahun pelajaran 2019/2020. Ha $_{a}$ menunjukkan adanya pengaruh yang signifikan antara permainan engklek dengan aktivitas gerak lompat tanpa awalan pada sisiwa kelas III Sekolah Dasar swasta amal bakti Tahun pelajaran 2019/2020 Sehingga dapat diambil sebuah kesimpulan permainan tradisional engklek berpengaruh secara signifikan terhadap aktivitas gerak dasar lompat pada siswa kelas III Sekolah Dasar swasta amal bakti Tahun Pelajaran 2019/2020.

\section{PENUTUP}

Berdasarkan pengujian hipotesis dapat ditarik sebuah kesimpulan bahwa permainan tradisional engklek berpengaruh secara signifikan terhadap aktivitas gerak dasar lompat pada siswa kelas III Sekolah Dasar swasta amal bakti Tahun Pelajaran 2019/2020 .

Dipublikasikan Oleh :

UPT Publikasi dan Pengelolaan Jurnal

Universitas Islam Kalimantan Muhammad Arsyad Al-Banjari Banjarmasin 


\section{REFERENSI}

Ardiwinata, Achmad Allatief, (2006), Kumpulan Permainan Rakyat Olahraga Tradisional. Jakarta : Cerdas Jaya.

Dadang Masnun, (2003 ) “Kinesiology Olahraga” Jakarta: FIK UNJ.

Dinata, Marta. (2003) “Permainan Kecil dan Permainan Tradisional”. Bandar Lampung.

Suharsimi Arikunto (2006). Penelitian Tindakan Kelas. Bandung Yrama Widia.

Sukintaka, (2004) Filosofi, Pembelajaran, dan Masa Depan Teori Pendidikan Jasmani. Jakarta: Nuansa.

Syarifudin, (2001) Kemampuan Gerak dan Program Pembelajaran Pendidikan Jasmani, Jurnal IPTEK Olahraga, Volume 4 Nomor 3. Jakarta: Pusat Pengkajian dan Pengembangan IPTEK Olahraga Ditjen Olahraga Depdiknas.

Tangkudung James, (2012) Kepelatihan Olahraga ’Pembinaan Prestasi Olahraga” Jakarta: Penerbit Cerdas Jaya

Widiastuti, (2011). Tes dan Pengukuran Olahraga. Jakrta :PT Bumi Putra.

Dipublikasikan Oleh :

UPT Publikasi dan Pengelolaan Jurnal

Universitas Islam Kalimantan Muhammad Arsyad Al-Banjari Banjarmasin 